\title{
AVALIAÇÃO DO EFEITO DA CONCENTRAÇÃO DE CARBONATO NA ELETRODEPOSIÇÃO DE COBRE SOBRE DISCOS DE AÇO-CARBONO
}

\author{
Angélica Inês Ferreira da Silva e Júlio Carlos Afonso* \\ Departamento de Química Analítica, Instituto de Química, Universidade Federal do Rio de Janeiro, Av. Athos da Silveira Ramos, \\ 149, Bloco A, 21941-909 Rio de Janeiro - RJ, Brasil \\ Luis Gonzaga Santos Sobral \\ Centro de Tecnologia Mineral/Ministério da Ciência e Tecnologia, Av. Pedro Calmon, 900, Cidade Universitária, 21941-908 Rio \\ de Janeiro - RJ, Brasil
}

Recebido em 19/6/07; aceito em 7/3/08; publicado na web em 3/10/08

\begin{abstract}
EVALUATION OF THE EFFECT OF CARBONATE CONCENTRATION IN THE COPPER ELECTRODEPOSITION ON MILD STEEL BLANKETS. Mild steel blankets were covered with electrolytic copper thin layer, from cyanide bath, being evaluated the influence of the carbonate concentration in the physiochemical properties of those deposits. The cell voltage decreased as the current intensity decreased, but the adherence of the deposit was not enhanced, showing that the increment of carbonate concentration causes substantial problems. Chemical solubilization reactions of air-bearing carbon dioxide and oxidation of free cyanide ions through dissolved oxygen evolved in the anodic processes contribute to the copper plating to occur in an inefficient way. The best optimal conditions require a carbonate concentration below $50 \mathrm{~g} \mathrm{~L}^{-1}$.
\end{abstract}

Keywords: copper plating; carbonate; blanket.

\section{INTRODUÇÃO}

O conceito de eletrodeposição de metais é usado para definir a redução eletrolítica de um dado elemento, inicialmente na forma iônica, na superfície de um substrato metálico ou de natureza condutora, como resultado da migração de íons do metal de interesse (sob a ação de uma corrente elétrica), em solução aquosa, com a finalidade de proteger o substrato menos nobre contra os processos corrosivos a que estão sujeitas essas estruturas metálicas, bem como para conferir o acabamento superficial necessário para agregar valores comerciais. ${ }^{1}$ Na eletrodeposição, utiliza-se uma célula eletrolítica contendo um eletrólito, constituído de sais iônicos do metal a ser depositado, também conhecido como banho. Os banhos mais utilizados em eletrodeposição são os inorgânicos, como os de cobre, cromo, estanho, níquel, zinco, metais nobres (ouro, prata, ródio, platina, etc.) e ligas cobre/estanho, zinco/ferro, zinco/níquel e zinco/cobalto. ${ }^{2}$ A demanda desta técnica está na diversidade de acabamentos, permitindo a sua aplicação, tanto na parte de estética (por exemplo, fabricação de jóias), como na área de corrosão (ferramentas e peças automotivas). ${ }^{3,4}$

Dentre os processos de proteção de substratos de aço-carbono a cobreação ocupa um lugar de destaque. ${ }^{5}$ Em muitos casos ela constitui uma camada intermediária ótima para a subseqüente niquelação: depósitos de cobre-níquel-cromo sobre aço-carbono proporcionam proteção e estética notáveis, o que justifica seu amplo emprego na atualidade. ${ }^{5,6}$ A proteção do cobre eletrodepositado sobre ferro é de caráter catódico. O filme de cobre deve ser espesso e compacto, isto é, com porosidade mínima, para proporcionar máxima proteção. ${ }^{6}$

A cobreação é largamente empregada como camada intermediária nos procedimentos de deposição de níquel, prata, ouro, etc., em alumínio e suas ligas, no zinco e suas ligas (peças por extrusão), e nas ligas com alta percentagem de chumbo ou de antimônio, sobre as quais não seria possível a eletrodeposição de outros metais sem prejudicar sua aderência. $^{7}$

*e-mail:julio@iq.ufrj.br
O cobre pode ser eletrodepositado por intermédio de soluções, onde se encontra no estado divalente ou monovalente. No primeiro caso utilizam-se banhos à base de sulfato (os mais comuns), de fluoroborato, de sulfamato, etc.; no segundo caso, os banhos são cianídricos. ${ }^{1,48}$ Os banhos à base de sulfato possuem a vantagem de apresentarem menor custo, boa estabilidade química e serem relativamente mais fáceis de trabalhar por apresentarem menor toxicidade. Mas, apesar de possuírem tais vantagens, os banhos à base de cianeto continuam tendo um maior emprego, principalmente para substratos de zinco, aço ou alumínio, ${ }^{6}$ porque os depósitos obtidos são altamente aderentes, relativamente uniformes e morfologicamente mais coerentes (grãos mais finos). ${ }^{8-13} \mathrm{Os}$ banhos cianídricos de cobre são potencialmente mais tóxicos, exigindo medidas de segurança estritas para seu manuseio. . $^{13,14}$

Com o intuito de verificar a resistência dos recobrimentos metálicos utilizam-se testes, nos quais a peça é colocada numa câmara fechada contendo vapores de uma solução de cloreto de sódio (Câmara de salt-spray) ou anidrido sulfuroso (Câmara de Kersternich), simulando atmosferas altamente agressivas. ${ }^{15}$

A espessura da película (camada depositada) e suas propriedades dependem de diversos fatores: densidade da corrente aplicada, concentração dos sais, temperatura do banho, presença de aditivos, natureza do metal de base, agitação do banho, $\mathrm{pH}$ etc. ${ }^{12,13,16} \mathrm{~A}$ quantidade de metal eletrodepositado determina a massa e as dimensões finais das peças tratadas. Por isso, a quantidade de depósito tem que ser controlada dentro de tolerâncias muito restritas para que a peça final esteja dentro de suas especificações. ${ }^{16,17}$

\section{Os banhos de cobre cianídricos}

Apresentam, em geral, os seguintes componentes: cianeto de cobre(I); cianeto de sódio ou potássio; hidróxido de sódio ou potássio; carbonato de sódio ou potássio; sal de Rochelle (tartarato de sódio e potássio). ${ }^{18} \mathrm{Na}$ prática as formulações variam muito. Os sais de potássio são mais solúveis em água, permitindo o uso de maiores densidades de corrente operacionais. ${ }^{9}, 10,18$ 
O cianeto de cobre $(\mathrm{I})(\mathrm{CuCN})$ fornece os íons de cobre necessários para a deposição do metal. Este sal é solúvel em solução de cianeto alcalino, devido à formação de cianocomplexos de cobre. Quando este sal está em excesso, a quase totalidade do cobre está presente na forma de $\left[\mathrm{Cu}(\mathrm{CN})_{3}\right]^{2-}$, devido ao fato deste complexo ser o mais estável dentre todos os formados. ${ }^{9}{ }^{10,15}$ Além disso, ${ }^{19}$ se no banho não houver uma quantidade suficiente de cianeto livre pode ocorrer a precipitação do $\mathrm{CuCN}$ na superfície do ânodo, formando uma camada aderente a ponto de tornar o ânodo passivado ou polarizado, fato indesejado, pois dificulta a reação de corrosão do mesmo e diminui a eficiência de corrente anódica.

A situação ideal é abaixar o potencial de redução do cobre para um valor inferior ao do ferro. Nestas condições ocorre apenas a deposição do cobre por eletrodeposição, cessando a deposição por deslocamento galvânico. ${ }^{18} \mathrm{~A}$ adição de cianeto em excesso nos banhos de cobre determina a diminuição do caráter nobre do metal (diminuição do potencial de redução). Isso permite a obtenção de depósitos cada vez mais aderentes. ${ }^{20}$ Uma vez obtido um depósito não aderente, as camadas eletrodepositadas obtidas não serão aderentes. ${ }^{18,20} \mathrm{Na}$ eletrodeposição os íons cianeto são adsorvidos na superfície da peça (cátodo) favorecendo a obtenção de depósitos de granulação mais fina, ou seja, mais brilhantes. ${ }^{21}$

O hidróxido de potássio mantém o $\mathrm{pH}$ muito alcalino (> 13), evitando que o cianocomplexo de cobre se decomponha com liberação de gás cianídrico. $\mathrm{O}$ pH elevado inibe a formação de carbonatos devido à decomposição do cianeto: nessa situação ocorre a absorção de $\mathrm{CO}_{2}$ presente no ar que, por reação com cianeto, forma carbonato e libera gás cianídrico. ${ }^{17,18,20}$

A presença de carbonatos alcalinos (até $60 \mathrm{~g} \mathrm{~L}^{-1}$ ) apresenta algumas vantagens: ${ }^{13,22}$ aumenta a condutividade do banho; mantém o pH do banho constante, ou seja, tem um efeito tamponante sobre o meio; aumenta a polarização catódica, melhorando o poder de penetração; diminui a polarização anódica, possivelmente formando, com os íons metálicos liberados pelo ânodo, carbonatos complexos; aumenta o valor máximo da densidade de corrente anódica operacional.

\section{Eletroquímica dos processos de eletrodeposição de cobre em meio cianídrico ${ }^{13,22}$}

\section{Reações catódicas}

A deposição do cobre pode ser descrita como segue:

$\mathrm{K}_{2} \mathrm{Cu}(\mathrm{CN})_{3}+\mathrm{e} \Leftrightarrow \mathrm{Cu}^{0}+2 \mathrm{KCN}+\mathrm{CN}^{-}$

concomitante com o desprendimento de gás hidrogênio, segundo:

$4 \mathrm{H}_{2} \mathrm{O}+4 \mathrm{e} \Leftrightarrow 4 \mathrm{OH}^{-}+2 \mathrm{H}_{2} \uparrow$

O desprendimento de hidrogênio é responsável pelo consumo de mais de $20 \%$ da corrente utilizada na eletrodeposição.

\section{Reações anódicas}

A dissolução do cobre contido no ânodo é representada pelo inverso da reação catódica, com consumo do cianeto liberado no cátodo de acordo com a seguinte reação:

$\mathrm{Cu}^{0}+2 \mathrm{KCN}+\mathrm{CN}^{-} \Leftrightarrow \mathrm{K}_{2} \mathrm{Cu}(\mathrm{CN})_{3}+\mathrm{e}$

outra reação paralela no ânodo é a libertação do oxigênio:

$4 \mathrm{OH}^{-} \Leftrightarrow 2 \mathrm{H}_{2} \mathrm{O}+\mathrm{O}_{2} \uparrow+4 \mathrm{e}$

Uma outra reação importante que se dá no ânodo é a oxidação do cianeto a cianato:
$\mathrm{KCN}+2 \mathrm{OH}^{-} \rightarrow \mathrm{KCNO}+\mathrm{H}_{2} \mathrm{O}+2 \mathrm{e}$

A subseqüiente hidrólise do cianato dá origem a bicarbonato e amônia:

$\mathrm{KCNO}+2 \mathrm{H}_{2} \mathrm{O} \rightarrow \mathrm{KHCO}_{3}+\mathrm{NH}_{3}$

O bicarbonato por sua vez reage com hidróxido de potássio dando carbonato:

$\mathrm{KHCO}_{3}+\mathrm{KOH} \rightarrow \mathrm{K}_{2} \mathrm{CO}_{3}+\mathrm{H}_{2} \mathrm{O}$

Na reação envolvendo a oxidação anódica e a subseqüente hidrólise do cianato, o desprendimento de hidrogênio no cátodo e o consumo de hidróxido de potássio pode ser resumido da seguinte forma:

$\mathrm{KCN}+\mathrm{KOH}+2 \mathrm{H}_{2} \mathrm{O} \rightarrow \mathrm{K}_{2} \mathrm{CO}_{3}+\mathrm{NH}_{3}+\mathrm{H}_{2} \uparrow$

Com a elevada alcalinidade do banho, uma grande parte da amônia se volatiliza de tal modo que a sua concentração é inferior a $1 \mathrm{~g} \mathrm{~L}^{-1}$. As reações de oxidação do cianeto a cianato e a subseqüente formação de carbonato são favorecidas pela alta temperatura e pelo aumento da intensidade de corrente no ânodo.

Uma outra reação possível é a hidrólise do cianeto sem oxidação: ${ }^{13}$

$\mathrm{KCN}+2 \mathrm{H}_{2} \mathrm{O} \rightarrow \mathrm{HCOOK}+\mathrm{NH}_{3}$

o formiato de potássio formado é muito solúvel e é bastante estável mesmo em temperaturas elevadas, acumulando-se no banho durante a eletrólise..$^{23}$

\section{A presença de carbonato nos banhos cianídricos}

Os banhos alcalinos à base de cianeto possuem o inconveniente de sofrerem carbonatação gradativa, ou seja, mesmo que os banhos não sejam formulados inicialmente com carbonato, este íon é formado gradativamente no banho mediante vários mecanismos. ${ }^{13}$ Pode ocorrer a decomposição do cianeto pelo dióxido de carbono absorvido do ar:

$2 \mathrm{KCN}+\mathrm{CO}_{2}+\mathrm{H}_{2} \mathrm{O} \rightarrow \mathrm{K}_{2} \mathrm{CO}_{3}+2 \mathrm{HCN}$

a reação do hidróxido com o dióxido de carbono absorvido do ar ocorre segundo a reação:

$2 \mathrm{KOH}+\mathrm{CO}_{2} \rightarrow \mathrm{K}_{2} \mathrm{CO}_{3}+\mathrm{H}_{2} \mathrm{O}$

a hidrólise do cianeto se dá com formação de amônia e formiato:

$\mathrm{KCN}+2 \mathrm{H}_{2} \mathrm{O} \rightarrow \mathrm{HCOOK}+\mathrm{NH}_{3} \uparrow$

o formiato sofre oxidação gradativa a carbonato, tanto eletroquímica como quimicamente:

$\mathrm{HCOOK}+\mathrm{KOH} \rightarrow \mathrm{K}_{2} \mathrm{CO}_{3}+\mathrm{H}_{2} \uparrow$

$1 / 2 \mathrm{O}_{2}+\mathrm{HCOOK}+\mathrm{e} \rightarrow \mathrm{CO}_{3}{ }^{2-}+\mathrm{K}^{+}+1 / 2 \mathrm{H}_{2} \uparrow$

e ainda ocorre a reação do cianeto com o hidróxido, na presença de oxigênio dissolvido:

$2 \mathrm{KCN}+2 \mathrm{H}_{2} \mathrm{O}+2 \mathrm{KOH}+\mathrm{O}_{2} \rightarrow \mathrm{K}_{2} \mathrm{CO}_{3}+\mathrm{NH}_{3} \uparrow$ 
Os dois primeiros mecanismos (reações 10 e 11) são os mais importantes nas condições operacionais dos banhos eletrolíticos cianídricos. Portanto, toda ação que evite a absorção de $\mathrm{CO}_{2}$ restringe a formação de carbonatos.

A formação de carbonato é favorecida: ${ }^{20-22}$ pelo aumento da temperatura, principalmente para valores superiores a $71^{\circ} \mathrm{C}$. Por esta razão a temperatura do banho deve ser rigorosamente controlada e mantida abaixo deste valor; com a utilização de altas densidades de corrente, pois isso requer aumento concomitante da temperatura e da agitação; com a agitação do banho, principalmente quando feita por injeção de ar; com o aumento da concentração dos constituintes do banho.

O aumento excessivo do teor de carbonatos causa diversos efeitos adversos no processo de eletrodeposição: ${ }^{13,24}$ redução da faixa operacional de densidade de corrente catódica; produção de depósitos ásperos, devido à formação de partículas de carbonatos insolúveis que são incorporadas aos depósitos; diminuição de brilho do depósito; aumento da viscosidade do banho, o que determina o aumento da perda por arraste (drag-out) na operação de lavagem das peças acabadas; diminuição da eficiência de corrente catódica.

Existem dois métodos para a diminuição da concentração de carbonatos: o resfriamento da solução e a precipitação química. ${ }^{25}$ O primeiro baseia-se no abaixamento da temperatura do banho até a cristalização do carbonato. Somente os banhos à base de sódio podem ser tratados por este método, devido à elevada solubilidade do carbonato de potássio. O segundo baseia-se na precipitação do carbonato, utilizando principalmente óxido de cálcio, sulfato de cálcio, hidróxido de cálcio ou bário, cianeto de cálcio ou bário. Ambos possuem vantagens e desvantagens e a escolha adequada deverá pautar-se nas condições do processo.

\section{Padrão das moedas brasileiras}

As moedas que circulam em um país são chamadas moedas de circulação corrente, fabricadas em alta escala de produção. Podem ser feitas a partir de discos de ligas maciças ou homogêneas (tipo I), discos com revestimento do tipo sanduíche ou clads (tipo II) e com discos eletrodepositados (tipo III). ${ }^{26,27}$

Os Estados Unidos e atualmente a Comunidade Européia utilizam os discos do tipo II, que possuem vantagens como: alta segurança contra fraudes e falsificações devido à exclusividade do material tricamada e ao formato de disco exclusivo para uso em máquinas de venda automática, principalmente para moedas de alta denominação. ${ }^{27}$

Os discos do tipo I já foram os mais comuns no Brasil. No período de 1899 até 1998 , foram utilizadas várias ligas metálicas e metais isolados como, por exemplo, ouro, prata, ligas de cobre (bronze, latão, cupro-níquel, bronze-alumínio), níquel, alumínio e aço inoxidável. ${ }^{27}$ Os discos do tipo III foram lançados no Brasil em julho de 1998 na segunda geração de moedas do Real. Este tipo de disco foi lançado nos anos 70 no Canadá. Entre as principais vantagens, citam-se: ${ }^{28,29}$ menor risco de desamoedamento, pois as moedas são fabricadas com um substrato de aço-carbono imobilizando menos de $10 \% \mathrm{~m} / \mathrm{m}$ de metais não ferrosos como cobre, níquel, estanho, ditos de grande valor estratégico; maior facilidade na distinção dos valores faciais das moedas pela variedade de coloração pelos idosos e deficientes visuais; aceitação das moedas com espessura mínima recomendada de camada eletrodepositada para uso em máquinas de venda automática; maior segurança contra fraudes e falsificações.

Os banhos utilizados na Casa da Moeda do Brasil são: os de cobre à base de cianeto para as moedas de $\mathrm{R} \$ 0,01 \mathrm{e} \mathrm{R} \$ 0,05 \mathrm{e}$, os de cobre/ estanho, também à base de cianeto, para as moedas de $\mathrm{R} \$ 0,10$ e $\mathrm{R} \$ 0,25$ e de $\mathrm{R} \$ 1,00$ (neste caso, somente a orla). As moedas de $\mathrm{R} \$ 0,01$ e de $\mathrm{R} \$ 0,05$ possuem camadas de 35 micrômetros (especificação) de cobre, cujos substratos são discos de aço baixo-carbono SAE 1006/1008. ${ }^{30}$

A decisão pelo uso de banhos à base de cianeto foi pautada principalmente na qualidade dos depósitos que deveriam ser obtidos. Outro argumento relevante é que este tipo de banho é o mais conhecido, difundido e praticado nas principais Casas da Moeda do mundo. A escolha de depósitos de cobre e bronze visava principalmente a obtenção de moedas com um aspecto bonito e que se diferenciassem da série anterior (toda feitas de aço inox). ${ }^{30}$

A literatura apresenta relativamente poucos trabalhos sobre a influência do carbonato no desempenho de banhos alcalinos à base de cianeto para eletrodeposição de metais. Em particular, os banhos cianídricos para deposição de ouro e prata utilizam elevadas concentrações de cianeto livre, visando o acabamento superficial de peças metálicas com depósitos delgados desses metais. Deve-se evitar o crescimento excessivo da concentração de carbonato para não comprometer a aderência desses depósitos. ${ }^{1}$ Trabalhos técnicos e publicações não científicas parecem ser as principais fontes de informações. Por isso, este trabalho apresenta um estudo detalhado da eletrodeposição de cobre a partir de um banho cianídrico em presença de carbonato. Numa primeira fase determinou-se a influência da concentração do íon carbonato sobre algumas variáveis do processo de cobreação: voltagem da célula, eficiências catódica e anódica. Num segundo momento, em um banho com alta concentração de carbonato, realizou-se uma série de eletrodeposições com valores decrescentes de intensidade da corrente aplicada. Em ambas as situações avaliou-se a qualidade do depósito obtido. O substrato escolhido é o aço-carbono. A escolha direcionada para a moeda de $\mathrm{R} \$ 0,01$ deveu-se à simplicidade de manuseio, ao custo mais baixo e à menor escala de trabalho. Além disso, a maior parte das observações deste estudo pode ser aplicada à linha de banhos de cobre/estanho, visto que a carbonatação excessiva nesse banho também traz problemas naquela linha de produção.

\section{PARTE EXPERIMENTAL}

\section{Matérias-primas}

Foi utilizado um banho alcalino de cobre à base de cianeto, formulado inicialmente com uma baixa concentração de carbonato, que foi aumentada por adições externas, a cada experimento. As concentrações dos demais componentes não foram variadas. Não foi adicionado nenhum aditivo ao banho. A Tabela 1 mostra a composição inicial do banho utilizado.

A eletrodeposição de cobre foi efetuada sobre discos de $\mathrm{R} \$ 0,01$ (liga de aço baixo-carbono SAE 1006/1008) com as seguintes características: massa individual (g): 2,25 $\pm 0,07$; diâmetro orlado (mm): $16,63 \pm 0,05$; espessura no centro $(\mathrm{mm}): 1,30 \pm 0,04$; espessura na orla $(\mathrm{mm}): 1,54 \pm 0,15$. A análise química dos discos encontra-se na Tabela 2. Utilizou-se como ânodo, nos testes de eletrodeposição, cilindros de cobre puro, tipo OFHC (oxygen free, high conductivity). A Tabela 2 apresenta a análise química do cobre.

Tabela 1. Composição inicial do banho de cobre para eletrodeposição

\begin{tabular}{lc}
\hline Componente & Valor praticado \\
\hline Cobre (como CuCN) & $24,5 \mathrm{~g} \mathrm{~L}^{-1}$ \\
Cianeto de potássio $(\mathrm{KCN})$ & $12,0 \mathrm{~g} \mathrm{~L}^{-1}$ \\
Hidróxido de potássio $(\mathrm{KOH})$ & $13,0 \mathrm{~g} \mathrm{~L}^{-1}$ \\
Carbonato de potássio $\left(\mathrm{K}_{2} \mathrm{CO}_{3}\right)$ & $20,0 \mathrm{~g} \mathrm{~L}^{-1}$ \\
Tempo & $4,46 \mathrm{~h}$ \\
Temperatura & $60{ }^{\circ} \mathrm{C}$ \\
\hline
\end{tabular}


Tabela 2. Análise química das matérias-primas usadas na eletrodeposição

\begin{tabular}{lccc}
\hline \multicolumn{2}{l}{$\begin{array}{l}\text { Discos de aço baixo-carbono } \\
\text { Elemento }\end{array}$} & \multicolumn{2}{c}{ Cobre } \\
\hline $\mathrm{C}$ & $0,06 \mathrm{~m} / \mathrm{m} 0,08$ & Elemento & $\% \mathrm{~m} / \mathrm{m}$ \\
$\mathrm{Mn}$ & 0,24 a 0,45 & $\mathrm{Cu}$ & 99,95 (min.) \\
$\mathrm{P}$ & 0,04 (máx.) & $\mathrm{Pb}$ & 0,004 (máx.) \\
$\mathrm{S}$ & 0,05 (máx.) & $\mathrm{S}$ & 0,002 (máx.) \\
$\mathrm{Si}$ & 0,10 (máx.) & $\mathrm{Fe}$ & 0,003 (máx.) \\
& & $\mathrm{Sb}$ & 0,002 (máx.) \\
& & $\mathrm{Ni}$ & 0,002 (máx.) \\
& & $\mathrm{Bi}$ & 0,003 (máx.) \\
\hline
\end{tabular}

\section{Sistema reacional}

A aparelhagem utilizada na eletrodeposição do cobre consiste basicamente de um suporte, uma cuba para eletrodeposição (50 L de capacidade) contendo o banho de cobre, um tambor rotatório (com capacidade de $1 \mathrm{~kg}$ de peças (cátodo) a serem tratadas) com controlador de velocidade e, também, um dispositivo controlador de temperatura. Para o monitoramento da voltagem da célula eletrolítica foi utilizado um multímetro digital. Para a circulação do banho foi utilizada uma bomba magnética. Os cilindros de cobre que compõem a área anódica foram dispostos em dois cestos de titânio, colocados dentro da cuba, lado a lado do tambor. De acordo com a literatura, a área anódica precisa ser no mínimo duas vezes a área catódica praticada. ${ }^{6,15,31}$ Neste trabalho, a área anódica é três vezes a área catódica. Para a etapa de desengraxe eletrolítico (realizada anteriormente à eletrodeposição) foi utilizado o mesmo tambor rotatório supracitado, porém utilizando uma célula confeccionada em polipropileno contendo a solução desengraxante. Para o aquecimento deste sistema foi utilizada uma resistência elétrica revestida em teflon. Para servir como cátodo foram acopladas, dentro da cuba, duas placas de aço inox, uma de cada lado do tambor. Nesta etapa, o ajuste da temperatura foi realizado com a ajuda de um termômetro de mercúrio.

Procurou-se trabalhar dentro da rotina praticada na Casa da Moeda do Brasil, ajustando-se somente as intensidades de corrente de desengraxe eletrolítico e eletrodeposição de cobre face às proporções das escalas de produção e de laboratório.

\section{Procedimento experimental}

Em uma balança analítica, pesou-se $1 \mathrm{~kg}$ de discos de aço baixocarbono, os quais foram lavados com água destilada $\left(60^{\circ} \mathrm{C}\right)$ para retirar parte da substância protetora dos discos, que é uma substância solúvel em água, cuja única função é proteger a integridade dos discos durante o transporte. Foram também pesados $11 \mathrm{~kg}$ de cobre metálico.

Após escoamento da água, transferiram-se os discos para o tambor rotatório para a etapa de desengraxe eletrolítico (concentração de desengraxante alcalino, $100 \mathrm{~g} \mathrm{~L}^{-1} ; 55^{\circ} \mathrm{C}$; corrente de $2,5 \mathrm{~A}$; tempo $2,5 \mathrm{~min})$. O objetivo é retirar gorduras e impurezas presentes na superfície do disco. ${ }^{20,28}$ Os discos foram exaustivamente lavados com água destilada $\left(60^{\circ} \mathrm{C}\right)$ para total retirada do desengraxante até que as águas de lavagem apresentassem $\mathrm{pH}=7$ (100 $\mathrm{mL} \mathrm{g}^{-1}$ de discos). Antes da próxima etapa, o tambor foi exaustivamente lavado com água corrente e por último com água destilada para eliminar qualquer vestígio da solução desengraxante.

Os discos lavados foram submetidos à decapagem com ácido clorídrico $\left(12 \mathrm{~g} \mathrm{~L}^{-1}\right)$ durante $5 \mathrm{~min}$, à temperatura ambiente. $\mathrm{O}$ objetivo é retirar óxidos que porventura estejam aderidos à superfície do disco. ${ }^{19,28}$ Eles foram em seguida lavados com água destilada (60 $\left.{ }^{\circ} \mathrm{C}\right)$ até que as águas de lavagem apresentassem $\mathrm{pH}=7\left(80 \mathrm{~mL} \mathrm{~g}^{-1}\right.$ discos). Os discos lavados foram rapidamente transferidos para o tambor rotatório para realizar a eletrodeposição. Após a decapagem a superfície dos discos torna-se muito ativa, sendo rapidamente atacada pelo oxigênio do ar. $\mathrm{O}$ tambor foi lacrado e então submergido na célula eletrolítica contendo o banho de cobre alcalino mantido a $60{ }^{\circ} \mathrm{C}$. Fixou-se a intensidade de corrente a ser utilizada durante o tempo de eletrodeposição calculado. $\mathrm{O}$ cobre foi transferindo em quantidades iguais para as duas cestas de titânio (ânodo), dispostas paralelamente, face a face com o tambor.

Numa primeira série de experimentos, variou-se a concentração de carbonato $\left(\mathrm{K}_{2} \mathrm{CO}_{3}\right)$ no banho $\left(20-400 \mathrm{~g} \mathrm{~L}^{-1}\right)$, mantidas fixas as concentrações de $\mathrm{KCN}$ e de cobre solúvel (Tabela 1), bem como a corrente aplicada (10 A) e as massas dos discos e do cobre. A densidade anódica utilizada foi de $0,143 \mathrm{~A} \mathrm{dm}^{-2}$. Partindo-se da especificação de percentual de camada (quantidade de cobre a ser depositada por unidade de disco) praticado na Casa da Moeda do Brasil $(7,4 \% \mathrm{~m} / \mathrm{m}$ de $\mathrm{Cu})$, da corrente aplicada (10 A) e de uma eficiência de corrente de $70 \%$, pode-se calcular o tempo de eletrodeposição para $1 \mathrm{~kg}$ de discos:

$74 \mathrm{~g}$ de $\mathrm{Cu}=2,372 \mathrm{~g} \mathrm{~A}^{-1} \mathrm{~h}^{-1} \times 10 \mathrm{~A} \times 0,7 \times \mathrm{t} \rightarrow \mathrm{t} \approx 4,46 \mathrm{~h}$

que é sensivelmente o mesmo aplicado na Casa da Moeda. Numa outra série de experimentos, fixou-se a concentração de carbonato (400 $\mathrm{g} \mathrm{L}^{-1}$ ), variando-se a corrente aplicada (4-10 A), o que exigiu o recálculo do tempo de eletrodeposição conforme cálculo acima.

Durante a eletrodeposição, colhia-se, de $1 \mathrm{em} 1 \mathrm{~h}$, uma amostra ( $5 \mathrm{~mL}$ ) do banho para controle analítico. A voltagem da célula foi registrada a cada $30 \mathrm{~min}$. Durante a eletrodeposição o volume do banho era, também, corrigido pela adição de água destilada devido à evaporação da mesma. Sempre antes de cada experimento a análise do experimento anterior era considerada para verificar a necessidade de correção na concentração dos componentes do banho, para que os mesmos permanecessem na faixa desejada.

Após o término da eletrodeposição, retiraram-se rapidamente os discos do tambor, promovendo a lavagem completa com água $\left(60^{\circ} \mathrm{C}\right)$. Em seguida foram secos com a ajuda de um secador, realizando-se rapidamente a pesagem, e guardando-os num dessecador sob vácuo, para a etapa de tratamento térmico. Separaram-se 4 discos eletrodepositados sem tratamento térmico para análise por microscopia eletrônica de varredura (ver adiante). Os mesmos procedimentos de lavagem, secagem e pesagem foram utilizados para o cobre.

O tratamento térmico foi efetuado na Casa da Moeda do Brasil, em um forno de recozimento. Ele foi purgado com nitrogênio. Em seguida ajustou-se a vazão de gás redutor $\left(30 \mathrm{~m}^{3} \mathrm{~L}^{-1}\right)$, vazão suficiente para não oxidar os discos. A temperatura de recozimento é de 250 ${ }^{\circ} \mathrm{C}$. O objetivo do tratamento térmico é refinar os grãos, tornando a superfície mais homogênea pela formação de uma camada de interdifusão e menos susceptível à corrosão. ${ }^{26,29}$

A etapa final de acabamento (polimento e secagem) também foi realizada na Casa da Moeda do Brasil, em uma politriz de pequeno porte, utilizada para testes. Os discos foram colocados dentro da cuba da politriz com água, sabão de polimento e $10 \mathrm{~kg}$ de esferas de aço. Em seguida realizou-se um enxágüe abundante com água destilada. Na segunda etapa o procedimento foi repetido só que ao invés de sabão, utilizou-se ácido cítrico. Após o enxágüe, os discos foram colocados dentro de um saco de flanela limpo e secados em uma centrífuga.

\section{Cálculo das eficiências catódica $\left(\varepsilon_{\mathrm{C}}\right)$ e anódica $\left(\varepsilon_{\mathrm{A}}\right)$}

A partir das fórmulas abaixo foram calculadas as eficiências catódica e anódica para cada teste de eletrodeposição de cobre: 
$\varepsilon_{C}$ (eficiência catódica) $=\frac{D_{D}-D_{S}}{2,372\left(\mathrm{~g} \mathrm{~A}^{-1} h^{-1}\right) I_{C}(A) t(h)}$

sendo: $D_{D}=$ massa dos discos com depósito de cobre; $D_{S}=$ massa dos discos sem depósito de cobre; 2,372 $\mathrm{g} \mathrm{A}^{-1} \mathrm{~h}^{-1}=$ equivalente eletroquímico para a redução de $\mathrm{Cu}^{+}$em meio cianídrico; $I_{C}(\mathrm{~A})=$ intensidade de corrente catódica; $t(h)=$ tempo de eletrodeposição.

$\varepsilon_{\mathrm{A}}($ eficiênci a anódica $)=\frac{\mathrm{A}_{\mathrm{A}}-\mathrm{A}_{\mathrm{D}}}{2,372\left(\mathrm{~g} \mathrm{~A}^{-1} \mathrm{~h}^{-1}\right) \mathrm{I}_{\mathrm{A}}(\mathrm{A}) \mathrm{t}(\mathrm{h})}$

onde: $A_{A}=$ massa do ânodo antes do início do processo de eletrodeposição de cobre; $\mathrm{A}_{\mathrm{D}}=$ massa do ânodo após o processo de eletrodeposição de cobre; $I_{A}(\mathrm{~A})=$ intensidade de corrente anódica; $t(h)=$ tempo de eletrodeposição.

Tais eficiências poderiam ser também calculadas utilizando a fórmula seguinte:

$E_{c}=\frac{V\left(C_{o}-C_{t}\right)}{\frac{1}{n F}} x \frac{1}{\int_{0}^{t} I(t) d t} x 100$

sendo: $\mathrm{V}=$ volume de eletrólito $(\mathrm{L}) ; C_{o}$ e $C_{t}=$ concentração de cobre no eletrólito no início e final da eletrólise $\left(\mathrm{mol} \mathrm{L}^{-1}\right) ; \mathrm{F}=$ constante de Faraday ( 96.490 Coulomb mol$^{-1}$ ); $n=$ número de elétrons envolvidos nas reações de redução ou oxidação; $I$ = intensidade de corrente (A).

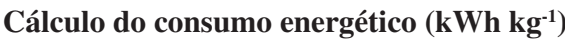

A partir da fórmula abaixo foram calculados os consumos energéticos referentes aos testes de eletrodeposição de cobre com relação às concentrações de carbonato:

consumo energético $=E \cdot \frac{n F}{M \cdot E C} \cdot \frac{100}{3600}\left(\mathrm{kWh} \mathrm{kg}^{-1}\right)$

onde: $E=$ voltagem da célula $(\mathrm{V}) ; n=$ número de elétrons envolvidos no processo de redução dos íons cuprosos; $M=$ átomo-grama do cobre

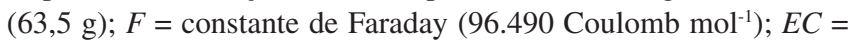
eficiência de corrente $(\%)$.

\section{Métodos analíticos}

Os sais de potássio (carbonato, hidróxido, cianeto) foram dosados pelos métodos clássicos de análise titulométrica. ${ }^{32} \mathrm{Em}$ todas as dosagens foram feitas duplicatas, sendo descontado o devido valor referente ao branco. No caso do carbonato, a amostra aquecida foi tratada com cloreto de bário $0,25 \mathrm{~mol} \mathrm{~L}^{-1}$, precipitando os íons carbonato na forma de $\mathrm{BaCO}_{3}$, que foi resfriado e filtrado. O precipitado foi suspenso em água e titulado com ácido clorídrico $0,25 \mathrm{~mol} \mathrm{~L}^{-1}$ até a viragem do indicador (alaranjado de metila). $\mathrm{O}$ cianeto foi titulado com nitrato de prata $0,1 \mathrm{~mol} \mathrm{~L}^{-1}$, utilizando como indicador solução de iodeto de potássio. O conteúdo de $\mathrm{KOH}$ foi determinado por titulação com solução $0,25 \mathrm{~mol} \mathrm{~L}^{-1}$ de ácido clorídrico, sendo o $\mathrm{pH}$ monitorado com um eletrodo de vidro.

O cobre foi analisado por espectrometria de absorção atômica (comprimento de onda 324,8 nm, limite de detecção 0,5 $\mathrm{mg} \mathrm{L}^{-1}$ ).

As análises de microscopia eletrônica de varredura (MEV) foram de dois tipos: análise superficial dos depósitos de cobre e análise da espessura desses depósitos. O equipamento utilizado foi um microscópio de varredura Leica 5440. A análise superficial visa a porosidade, a presença de precipitados e a uniformidade da superfície. Para isso separaram-se dois discos eletrodepositados de cada experimento, um sem tratamento térmico e outro com tratamento térmico. Os discos receberam um banho de prata, com a ajuda de um metalizador, pois alguns discos já apresentavam oxidação, e este óxido formado dificulta a condução de elétrons. Na análise da espessura, busca-se observar a homogeneidade da camada de cobre, isto é, verificar a existência de oclusões e a presença ou não de depósito pulverulento. Para tal separaram-se seis discos de cada experimento, três sem tratamento térmico e três com tratamento térmico. Como um dos objetivos era medir a espessura do depósito de cobre, submeteu-se cada lote de três discos tratados a um corte transversal, retirando-se 1/3 da moeda. Os outros $2 / 3$ da moeda foram imersos em uma resina e o conjunto foi seco e posteriormente polido para expor a superfície metálica do corte transversal. Em seguida, receberam uma cobertura de prata superficial com a ajuda de um metalizador, visto que a resina não é condutora.

\section{RESULTADOS E DISCUSSÃO}

\section{Variação da composição do banho com a eletrodeposição}

A partir das análises químicas dos constituintes do banho observou-se uma variação muito pequena da concentração de cada constituinte ao longo de cada teste de eletrodeposição de cobre, devendo-se levar em conta para isto a reposição constante de água à medida que esta evaporava. Essa observação se aplica tanto à série de experimentos onde se variou a concentração de carbonato como àquela em que se variou a corrente de eletrodeposição. É praxe que a composição de um banho se mantenha aproximadamente constante a fim de garantir uma eletrodeposição uniforme do metal. ${ }^{33}$

\section{Eficiências catódica $\left(\varepsilon_{\mathrm{C}}\right)$ e anódica $\left(\varepsilon_{\mathrm{A}}\right)$}

Tanto nos experimentos referentes ao efeito do aumento da concentração de carbonato, quanto naqueles onde se variou a intensidade da corrente aplicada, constatou-se claramente a influência direta da presença de carbonato no banho sobre a eficiência do processo eletrolítico: quanto maior a concentração de carbonato, menor a eficiência da eletrodeposição. ${ }^{13,24,33,34}$ Quando da diminuição da intensidade da corrente aplicada, observou-se também uma diminuição da eficiência de corrente, fato esse também em consonância com a literatura. ${ }^{34}$

\section{Consumo energético do processo}

O consumo energético decresceu com o aumento da concentração de carbonato, corroborando os resultados decrescentes das eficiências de corrente e os dados da literatura. ${ }^{34}$ Do mesmo modo, pelo menos na concentração de carbonato em $400 \mathrm{~g} \mathrm{~L}^{-1}$, o consumo energético foi reduzido quando a intensidade de corrente diminuiu, resultado esse em consonância com a correspondente redução da eficiência de corrente. .,34 $^{1,3}$

\section{Monitoramento da voltagem da célula eletrolítica}

A voltagem de uma célula é traduzida como a diferença de potencial entre os eletrodos (ânodo e cátodo) de uma célula eletroquímica e se refere usualmente às condições de não equilíbrio, quando corrente flui pela célula.

Como já era esperado, com base na literatura, o aumento da concentração de carbonato acarretou na diminuição da voltagem da célula, devido ao aumento da força iônica do eletrólito. ${ }^{13,33,34}$ Entretanto, o aumento dessa força iônica diminuiu a eficiência da corrente aplicada; em outras palavras, as reações paralelas envolvidas na formação de carbonato consomem corrente diminuindo a eficiência dos 
processos eletródicos de interesse, aumentando, conseqüentemente, o consumo de energia. ${ }^{13,33,34}$ A voltagem da célula também diminuiu com a redução da corrente aplicada na eletrodeposição. ${ }^{34}$

\section{Aspecto dos discos com depósito de cobre nos experimentos com variação da intensidade da corrente aplicada}

$\mathrm{Na}$ série de experimentos onde se variou a intensidade da corrente de eletrodeposição $\left(\left[\mathrm{CO}_{3}{ }^{2-}\right]=400 \mathrm{~g} \mathrm{~L}^{-1}\right)$, é claríssima a degradação da qualidade do depósito obtido com a redução da corrente aplicada (10-4 A), tornando os discos imprestáveis para uso na cunhagem das moedas. Somente as amostras submetidas à corrente de $10 \mathrm{~A}$ têm aspecto similar ao das moedas de $\mathrm{R} \$ 0,01$ em circulação. É preciso levar em conta a alta concentração de carbonato fixada neste teste, pois a literatura indica que em valores acima de $150 \mathrm{~g} \mathrm{~L}^{-1}$, a qualidade do depósito metálico cai drasticamente,$^{33}$ fato esse agravado caso haja redução da corrente aplicada. . $^{5,19,26,29,34}$

\section{Análise da superfície do cobre eletrodepositado}

A Figura 1 mostra a superfície dos depósitos de cobre obtidos em função da concentração de carbonato no banho. Na concentração de 50 $\mathrm{g} \mathrm{L}^{-1}$ (A), o depósito de cobre mostra-se bastante coeso e uniforme sem evidências da presença de porosidade. Contudo, com a concentração crescente de carbonato no banho, verificaram-se mudanças morfológicas marcantes nos depósitos de cobre, com indícios de surgimento de porosidade, a partir de valores de concentração de $300 \mathrm{~g} \mathrm{~L}^{-1}(\mathrm{~F})$. A literatura assinala que, para concentrações de carbonato a partir de 150 $\mathrm{g} \mathrm{L}^{-1}$, os depósitos de cobre perdem grandemente a sua qualidade:5,33,34 perda de aderência ao substrato, introdução de carbonatos na massa eletrodepositada e tamanho de partícula maior. De fato, no caso dos experimentos conduzidos com $350 \mathrm{~g} \mathrm{~L}^{-1}$ de carbonato $(\mathrm{G})$, surgiu um precipitado de carbonato de cálcio (ponto A). Adicionalmente, com o aumento da concentração para $400 \mathrm{~g} \mathrm{~L}^{-1}(\mathrm{H})$, a aderência do depósito de cobre ficou totalmente comprometida: houve desprendimento de pedaços de cobre eletrolítico pelo simples manuseio, deixando grande parte da superfície do disco de aço descoberta.
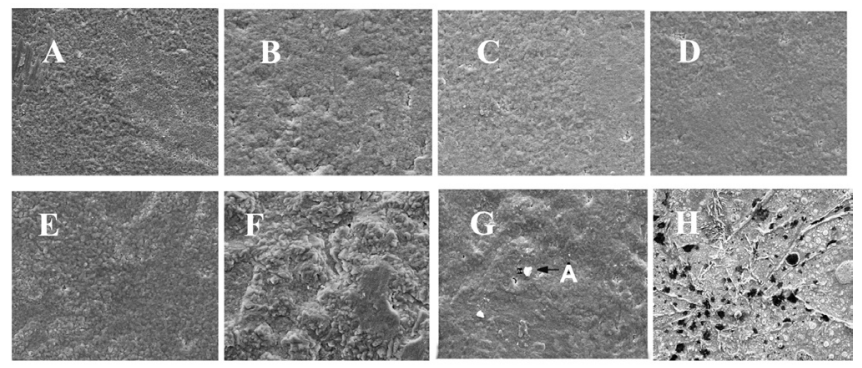

Figura 1. Depósitos de cobre (intensidade de corrente de $10 \mathrm{~A}$ ) obtidos sob diferentes concentrações de carbonato no banho: (A) $50 \mathrm{~g} \mathrm{~L}^{-1}$; (B) $100 \mathrm{~g}$ $L^{-1}$; (C) $150 \mathrm{~g} \mathrm{~L}^{-1}$; (D) $200 \mathrm{~g} \mathrm{~L}^{-1}$; (E) $250 \mathrm{~g} \mathrm{~L}^{-1}$; (F) $300 \mathrm{~g} \mathrm{~L}^{-1}$; (G) $350 \mathrm{~g} \mathrm{~L}^{-1}$; (H) $400 \mathrm{~g} \mathrm{~L}^{-1}$

Quando a intensidade de corrente foi reduzida de 10 para até 4 A (concentração de carbonato $400 \mathrm{~g} \mathrm{~L}^{-1}$ ), houve comprometimento total da aderência do depósito. Na corrente de $6 \mathrm{~A}$, o recobrimento da peça contém falhas. Quando a corrente foi fixada em 4 A, houve a formação de placas (lamelas) de cobre eletrolítico não aderentes à superfície dos discos (Figura 2): com a agitação do banho, essas placas se desprendiam, acumulando-se no fundo da célula de eletrodeposição, o que explica a coloração acinzentada dos discos. O efeito da corrente aplicada reflete-se particularmente no tamanho da partícula metálica eletrodepositada: quando maior a corrente, menor esse tamanho, pois é evitado nessas condições o crescimento dos cristais a partir do núcleo inicial, resultando em uma maior aderência ao substrato. ${ }^{5,33,34}$ Isso também se reflete num maior brilho da superfície, exatamente uma das características mais desejadas de um processo de eletrodeposição, ${ }^{1,3,4,15,20}$ e também na fabricação de moedas. ${ }^{18,26-29}$

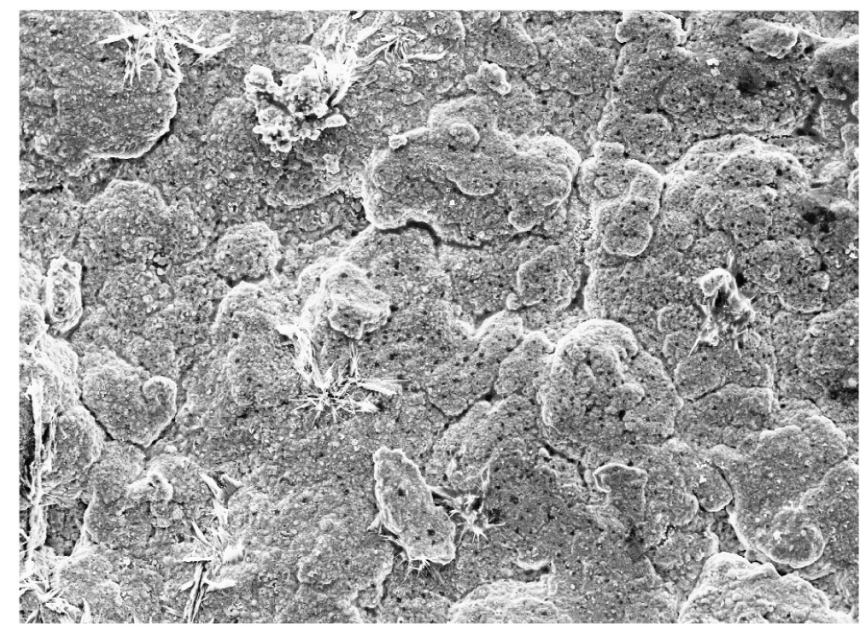

Figura 2. Foto da superfície do disco de aço-carbono com a cobertura deficiente dessa superfície pelo depósito lamelar não aderente de cobre eletrolítico sob corrente de $4 \mathrm{~A}$

A Figura 3 apresenta superfícies com depósitos de cobre eletrolítico provenientes dos testes com concentrações de carbonato de 20, 50, 300 e $350 \mathrm{~g} \mathrm{~L}^{-1}$, após tratamento térmico. Como pode ser observado no caso do emprego de uma baixa concentração de carbonato $\left(20 \mathrm{~g} \mathrm{~L}^{-1}\right)$ (A), após tratamento térmico, obteve-se uma superfície onde os grãos da superfície do cobre eletrolítico se apresentam bem definidos; com o aumento da concentração para $50 \mathrm{~g} \mathrm{~L}^{-1}$ (B), tem-se uma diminuição do tamanho dos grãos com o surgimento de depressões, fato que se intensificou quando do aumento da concentração a valores maiores (C e D). Esse resultado justifica a recomendação de se manter uma concentração de carbonato abaixo de 50-60 $\mathrm{g} \mathrm{L}^{-1}$ para garantir a homogeneidade do depósito, tanto do ponto de vista da superfície ${ }^{5,34}$ quanto do brilho obtido ${ }^{1,15,20,34}$.
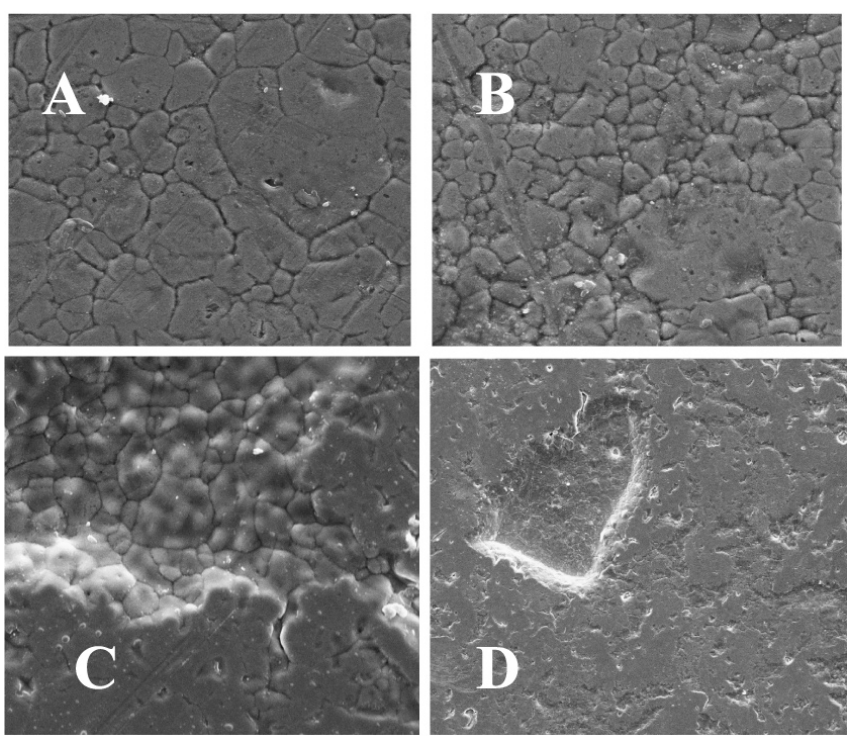

Figura 3. Fotos das superfícies dos discos recobertos com cobre sob diferentes concentrações de carbonato, após tratamento térmico a $250^{\circ} \mathrm{C}$ em atmosfera

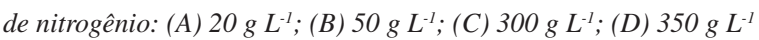




\section{Determinação da espessura dos depósitos de cobre}

A Figura 4a apresenta um corte transversal de um disco de aço

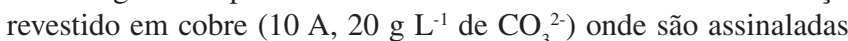
as espessuras do depósito de cobre em ambas as faces do disco. $\mathrm{O}$ depósito obtido é bastante compacto e homogêneo, com espessura uniforme. Nesse caso em particular, a concentração de carbonato estava em seu valor inferior $\left(20 \mathrm{~g} \mathrm{~L}^{-1}\right)$ e o disco não sofreu tratamento térmico posterior. Quando do tratamento térmico desse mesmo disco, a camada eletrodepositada se mostrou ainda mais homogênea com uma espessura menor, conforme apresentado na Figura 4b. Essa diminuição de espessura se explica pela interdifusão da camada de cobre com o substrato de aço-carbono, sendo também representativo de uma eletrodeposição bem feita e a obtenção de um produto de alta qualidade $1,3,4,15,20,34$.

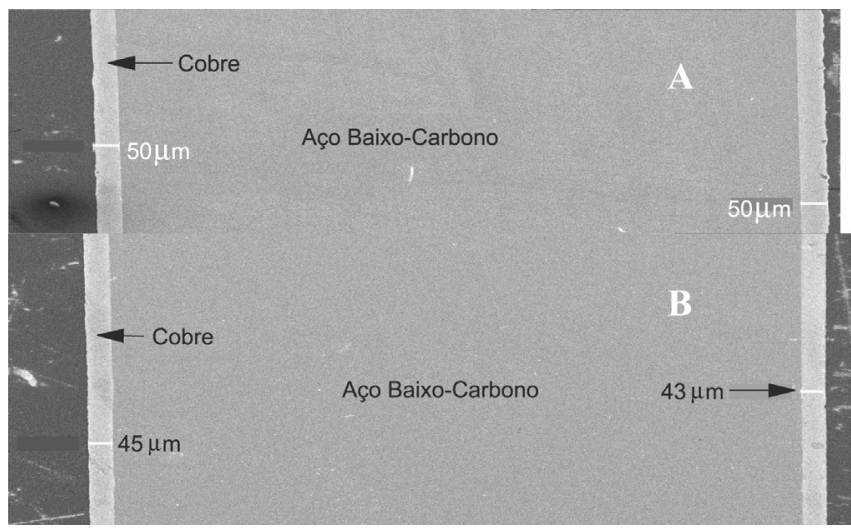

Figura 4. (A) Seção transversal do disco revestido com depósito de cobre $(I=$ $\left.10 \mathrm{~A} \mathrm{e}\left[\mathrm{CO}_{3}^{2-}\right]=20 \mathrm{~g} \mathrm{~L}^{-1}\right)$ antes do tratamento térmico; $(B)$ Seção transversal do mesmo disco após tratamento térmico

Quando a concentração de carbonato foi a $150 \mathrm{~g} \mathrm{~L}^{-1}$ o depósito começou a se deformar com relação ao perfil antes apresentando (Figura 5), em uma das faces do disco. Notou-se um depósito irregular que se traduz, numa escala macroscópica, numa superfície fosca acarretando a necessidade de um polimento mecânico posterior. Esse tratamento acaba por remover partículas de cobre comprometendo a espessura final do depósito de cobre afora o surgimento de porosidade nesse mesmo depósito. Isso também significa um aumento do custo do processo, um desperdício de material e a obtenção de produtos de qualidade inferior à desejada. ${ }^{1,20}$

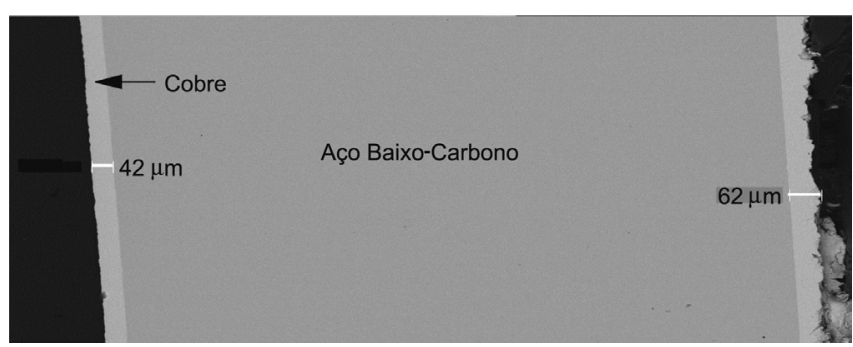

Figura 5. Seção transversal do disco revestido com depósito de cobre $(I=$ $\left.10 \mathrm{~A} \mathrm{e}\left[\mathrm{CO}_{3}^{2-}\right]=150 \mathrm{~g} \mathrm{~L}^{-1}\right)$ antes do tratamento térmico

Ao se elevar a concentração de carbonato a $350 \mathrm{~g} \mathrm{~L}^{-1}$ (Figura 6) houve danos severos ao processo eletrolítico de deposição de cobre, trazendo como consequiência o descolamento do depósito de cobre, comprometendo totalmente a aderência de tais depósitos e, conseqüentemente, inviabilizando a operação posterior de cunhagem na produção final de moedas. ${ }^{33-35}$

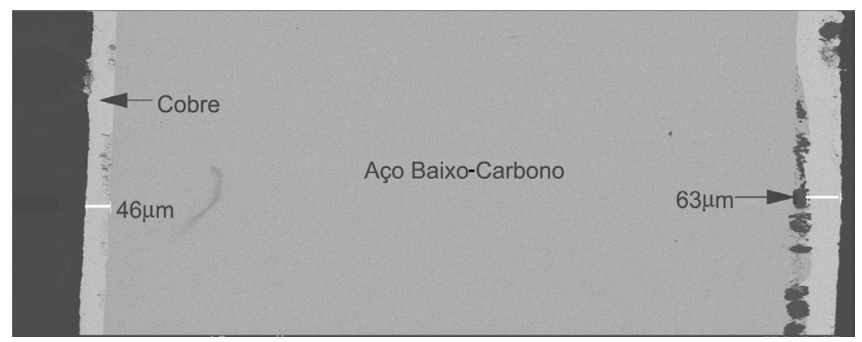

Figura 6. Seção transversal do disco revestido com depósito de cobre $(I=$ $\left.10 \mathrm{~A} \mathrm{e}\left[\mathrm{CO}_{3}^{2-}\right]=350 \mathrm{~g} \mathrm{~L}^{-1}\right)$ antes do tratamento térmico

\section{CONCLUSÕES}

A eletrodeposição de cobre sobre discos de aço baixo-carbono sob baixas concentrações de carbonato produziu peças onde a camada de cobre se mostrou aderente e homogênea. Afora isso, essa baixa concentração aumentou as eficiências catódica e anódica do processo. Contudo, na medida em que a concentração de carbonato se elevou no banho, outros fatores adversos passam a contribuir, de forma prejudicial, no processo de eletrodeposição de cobre. Um dos efeitos mais danosos que se pôde observar foi o comprometimento da aderência dos depósitos de cobre, fato que pode ser evidenciado pela observação, ao microscópio eletrônico de varredura, da seção transversal do disco revestido com cobre. Além disso, na maioria dos casos de testes com elevadas concentrações de carbonato, os depósitos apresentaram porosidade crescente. O surgimento de partículas de carbonatos (como $\mathrm{CaCO}_{3}$ ), que ancoraram na superfície dos discos, levou a irregularidades superficiais e, com isso, a produção de um depósito não uniforme e sem brilho.

\section{MATERIAL SUPLEMENTAR}

O material suplementar, disponível gratuitamente em http://quimicanova.sbq.org.br na forma de arquivo PDF, apresenta as seguintes informações: esquema da aparelhagem utilizada na eletrodeposição do cobre (Figura 1S); gráfico da variação da concentração dos constituintes do banho na série de experimentos onde se variou a concentração de carbonato (Figura 2S), ou a corrente de eletrodeposição (Figura $3 S$ ); gráfico das eficiências de corrente anódica e catódica em função da concentração de carbonato (Figura 4S), gráfico das eficiências de corrente anódica e catódica em função da intensidade da corrente aplicada (Figura 5S); consumo energético da eletrodeposição de cobre em função da concentração de carbonato (Tabela 1S) e da intensidade de corrente aplicada (Tabela $2 \mathrm{~S}$ ); gráfico da voltagem da célula em função da concentração de carbonato no banho (Figura 6S); gráfico da voltagem da célula em função da corrente aplicada (Figura 7S); aspecto visual dos discos de aço baixo-carbono recobertos com cobre para cada uma das intensidades de corrente de eletrodeposição testadas $\left(\left[\mathrm{CO}_{3}{ }^{2-}\right]=\right.$ $400 \mathrm{~g} \mathrm{~L}^{-1}$ ), em comparação com o substrato puro (Figura 8S); MEV de regiões de um disco cujo recobrimento com cobre eletrolítico (corrente 6 A) apresenta falhas (região A - Figura 9S).

\section{AGRADECIMENTOS}

A. I. F. da Silva agradece à FAPERJ, pela bolsa de Mestrado. À equipe da COAM (Coordenadoria de Análise Mineral) do CETEM pelas análises químicas necessárias a este trabalho. A O. da F. M. 
Gomes (Setor de Caracterização Tecnológica do CETEM), pelas análises de microscopia eletrônica. Ao Chefe do Departamento de Moedas e Medalhas, N. Santana. Ao Departamento de Moedas e Medalhas da Casa da Moeda do Brasil pelo apoio e informações prestadas para a condução desta pesquisa. A P. R. de M. Ferreira, Chefe do Laboratório Químico da Casa da Moeda do Brasil, pelo apoio dado para execução deste projeto e pelas contribuições sobre o tema deste trabalho.

\section{REFFERENCIAS}

1. Kanani, N.; Electroplating 2004, Elsevier: Amsterdam, 2004, cap. 3; Pecsok, R. L.; Shields, L. D.; Modern Methods of Chemical Analysis, $2^{\text {nd }}$ ed., John Wiley \& Sons: Nova Iorque, 1976, p. 335-338; Bard, A. J.; Faulkner, L. R.; Electrochemical Methods, Fundamentals and Applications, $2^{\text {nd }}$ ed., John Wiley \& Sons: Nova Iorque, 2001, p. 415-433; Bacquias, G.; Pratique et Conduite de Bains d'Éléctrolyse, Or et Alliages d'Or, BPI: Paris, 1977.

2. Rosso, M.; Electrochim. Acta 2007, 53, 250.

3. Talbot, D.; Talbot, J.; Corrosion Science \& Technology, CRC Press: Boca Raton, 1998.

4. Roth, E.; Galvanotécnica Prática, Editora Polígono: São Paulo, 1973, cap. 1,2 e 3.

5. Ibañez, A.; Fatás, E.; Surf. Coat. Technol. 2005, 191, 7.

6. Dudek, D. A.; Fedkiw, P. S.; J. Electroanal. Chem. 1999, 474, 16.

7. Soliman, H. M. A.; Appl. Surf. Sci. 2002, 195, 155.

8. Nelissen, G.; Theemsche, A. V.; Dan, C.; Van den Bossche, B.; Deconinck, J.; J. Electroanal. Chem. 2004, 563, 213.

9. Panossian, Z.; Tratamento de Superfície 1999, 93, 18.

10. Panossian, Z.; Tratamento de Superfície 1999, 94, 22.

11. Panossian, Z.; Corrosão e Proteção de Metais 2002, 21, 18.

12. Panossian, Z.; Corrosão e Proteção de Metais 2003, 22, 25.

13. Panossian, Z.; Tratamento de Superfície 2001, 108, 28.

14. Sinitski, R. E.; Srinivasan, V.; Haynes, R.; J. Electrochem. Soc. 1989, $127,47$.

15. Ahmed N. A. G.; Ion Plating Technology Developments and Applica- tions, John Wiley \& Sons: New York, 1987, p. 1-38 e 101-124.

16. D'alkaine, C. V.; Tulio, P. C.; Berton, M. A. C.; Electrochim. Acta 2004, 49, 1989.

17. Bertorelle, E.; Trattato de Galvanoplastia, Ulrico Hoelpi: Milano, 1974, cap. III; Kutzelnigg, A.; Ensayo de Recubrimento Metálico, Editoral River: Madrid, 1967.

18. Lowerheim, F. A.; Electroplating, McGraw-Hill: Nova Iorque, 1978.

19. Safranek, W. H.; The Properties of Electrodeposited Metals and Alloys, $2^{\text {nd }}$ ed., American Electroplaters and Surface Finishers Society: Orlando, 1986, p. $100-120$

20. Schlesinger, M.; Paunovic, M.; Modern Electroplating, $4^{\text {th }}$ ed., JohnWiley: Nova Iorque, 2000, cap. 2.

21. Horner, J.; Plat. Surf. Finish. 1998, 85, 42.

22. Geduld, H.; Met. Finish. 1967, 65, 52.

23. Myron C.; Crain, J. R.; US pat. 2,861,927 1958; Myron C.; Wenzel, L. B.; US pat. 2,858,257 1958.

24. Horner, J.; Plat. Surf. Finish. 1999, 86, 36.

25. www.wmrc.uiuc.edu/main_sections/info_services/library_docs/manuals/ finishing/plating.htm, acessada em Julho 2006.

26. Informação Técnica N 5085 - Coin Blanks From VDM, VDM: Bonn, 1986.

27. Gonçalves, C. B.; Casa da Moeda do Brasil, $2^{\mathrm{a}}$ ed., Casa da Moeda do Brasil: Rio de Janeiro, 1989.

28. Cribb, J.; Money, Eyewitness Guides: Londres, 1990.

29. Manual de Operação DVED 001/5, Westain: Toronto, 2000.

30. http://www.casadamoeda.com.br/produtos/prodmome.htm, acessada em Agosto 2007.

31. Chu, D., Fedkiw, P. S.; Electroanal. Chem. 1993, 345, 107.

32. Mendham, J.; Denney, R. C.; Barnes, J. D.; Thomas, M. J. K.; Vogel: Análise Química Quantitativa, 6 ${ }^{\mathrm{a}}$ ed., Livros Técnicos e Científicos: Rio de Janeiro, 2002; Day Jr., R. A.; Underwood, A. L.; Quantitative Analysis, $6^{\text {th }}$ ed., Prentice-Hall: New Jersey, 1991.

33. Managing Cyanide in Metal Finishing, The U.S. Environmental Protection Agency, Office of Research and Development: Cincinnati, 2004.

34. Mandich, N.; Met. Finish. 2005, 103, 18.

35. Hatherley, P. G.; Carpenter, P. J.; Trans. Inst. Met. Finish. 1995, 7, 85. 


\section{AVALIAÇÃO DO EFEITO DA CONCENTRAÇÃO DE CARBONATO NA ELETRODEPOSIÇÃO DE COBRE SOBRE DISCOS DE AÇO-CARBONO}

\section{Angélica Inês Ferreira da Silva e Júlio Carlos Afonso*}

Departamento de Química Analítica, Instituto de Química, Universidade Federal do Rio de Janeiro, Av. Athos da Silveira Ramos, 149, Bloco A, 21941-909 Rio de Janeiro - RJ, Brasil

Luis Gonzaga Santos Sobral

Centro de Tecnologia Mineral/Ministério da Ciência e Tecnologia, Av. Pedro Calmon, 900, Cidade Universitária, 21941-908 Rio de Janeiro - RJ, Brasil

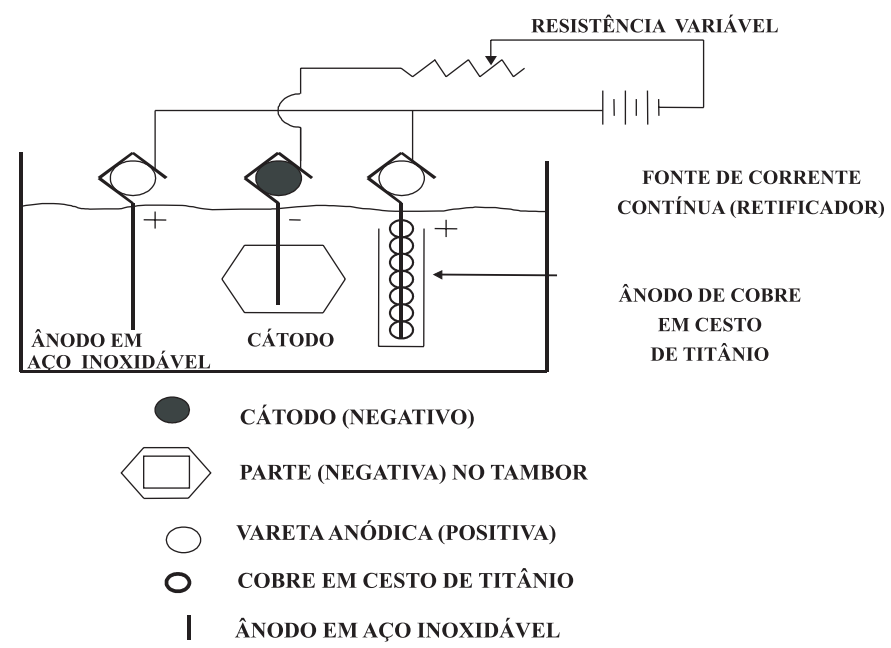

Figura 1S. Esquema do sistema reacional para o processo de eletrodeposição de cobre

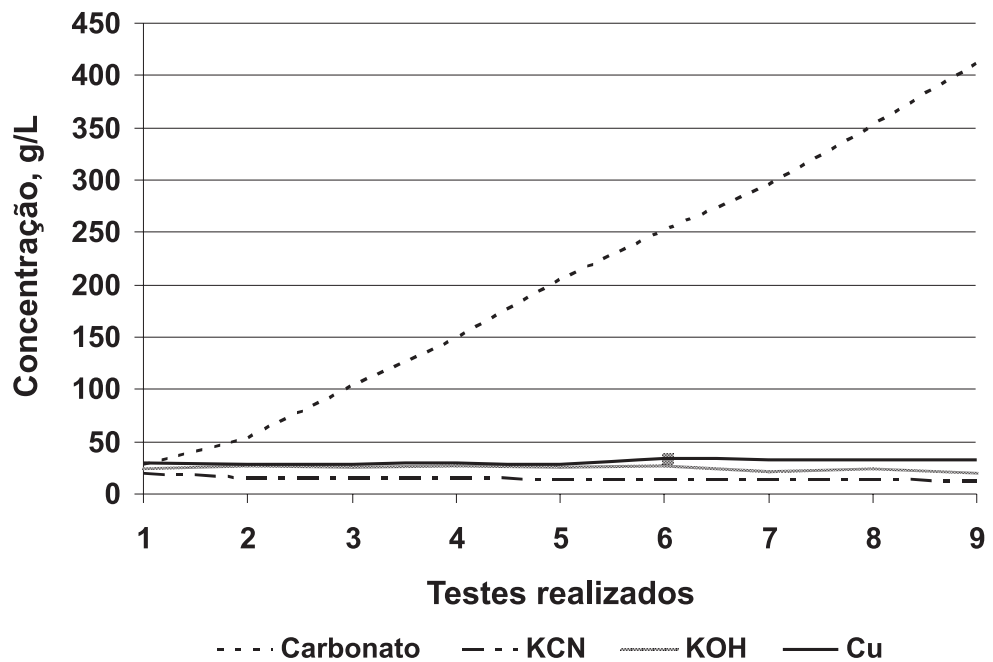

Figura 2S. Concentração dos constituintes do banho nos testes de avaliação da influência da concentração de carbonato na eletrodeposição de cobre $(I=10$ A): $1\left(20 \mathrm{~g} \mathrm{~L}^{-1}\right) ; 2\left(50 \mathrm{~g} \mathrm{~L}^{-1}\right) ; 3\left(100 \mathrm{~g} \mathrm{~L}^{-1}\right) ; 4\left(150 \mathrm{~g} \mathrm{~L}^{-1}\right) ; 5\left(200 \mathrm{~g} \mathrm{~L}^{-1}\right) ; 6\left(250 \mathrm{~g} \mathrm{~L}^{-1}\right) ; 7\left(300 \mathrm{~g} \mathrm{~L}^{-1}\right) ; 8\left(350 \mathrm{~g} \mathrm{~L}^{-1}\right) ; 9\left(400 \mathrm{~g} \mathrm{~L}^{-1}\right)$ 


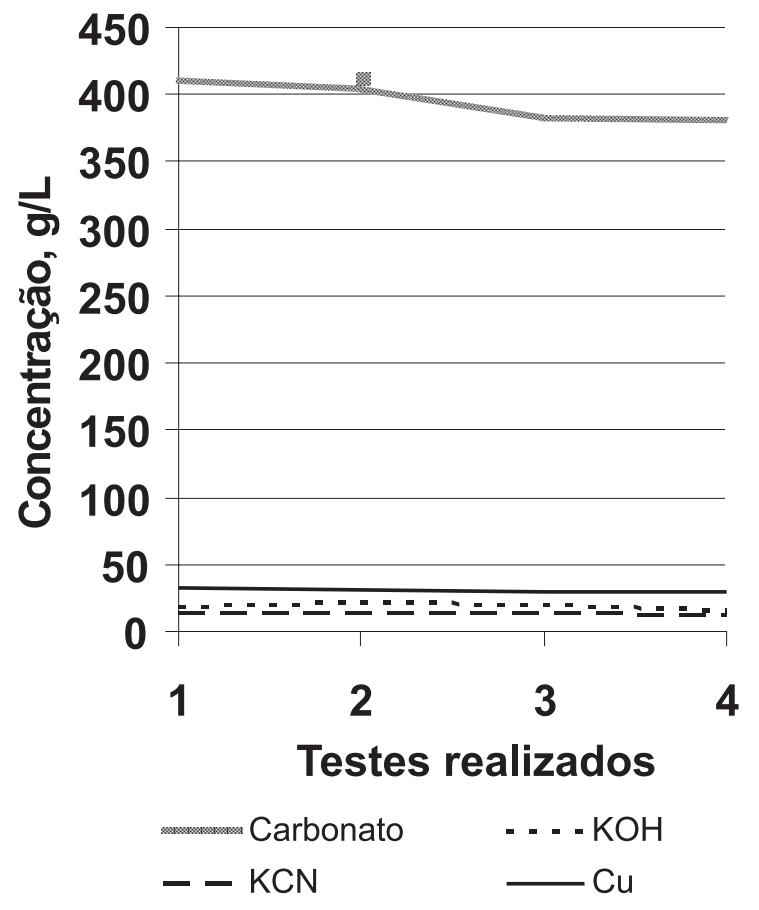

Figura 3S. Concentração dos constituintes do eletrólito nos testes de avaliação da influência da intensidade da corrente na eletrodeposição de cobre: 1 (10 A); 2 (8 A); $3(6 \mathrm{~A}) ; 4(4 \mathrm{~A})$. $\left[\mathrm{CO}_{3}^{2-}\right]=400 \mathrm{~g} \mathrm{~L}^{-1}$

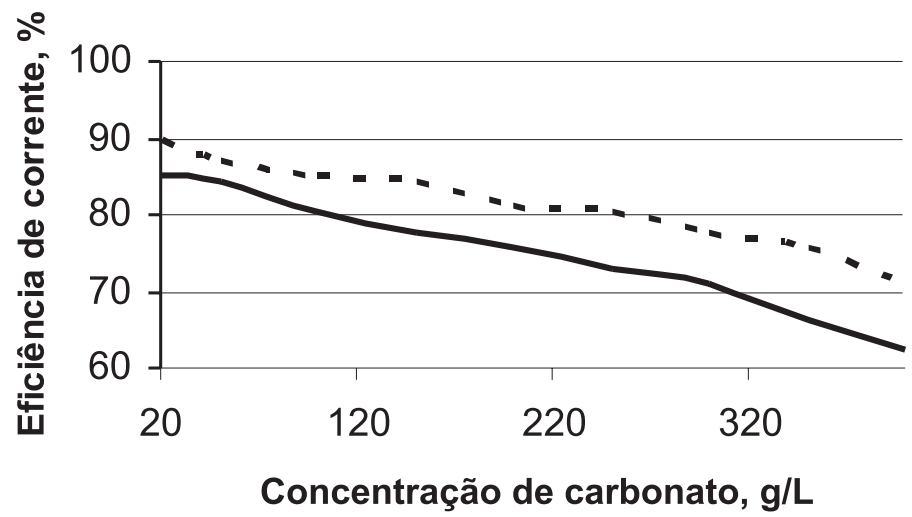

catódica - - - anódica

Figura 4S. Efeito da concentração de carbonato na eficiência das correntes catódica e anódica. $I=10 \AA$ 


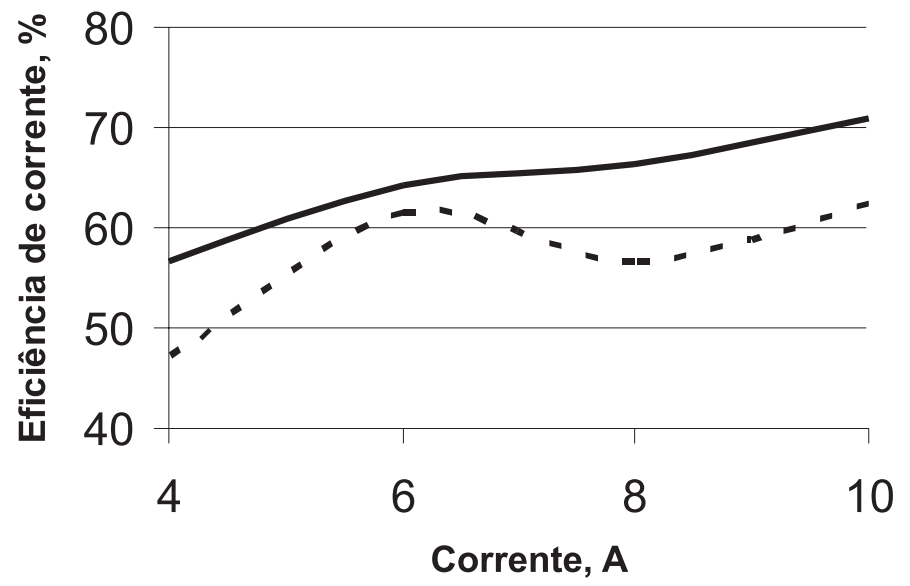

- - . catódica unódica

Figura 5S. Efeito da intensidade de corrente na eficiência das correntes catódica e anódica. $\left[\mathrm{CO}_{3}^{2-}\right]=400 \mathrm{~g} \mathrm{~L}^{-1}$

Tabela 1S. Consumo energético nos testes com variação da concentração de carbonato $(\mathrm{I}=10 \mathrm{~A})$

\begin{tabular}{lcc}
\hline$\left[\mathrm{CO}_{3}^{2-}\right], \mathrm{g} \mathrm{L}^{-1}$ & Consumo energético catódico $(\mathrm{KWh} / \mathrm{Kg} \mathrm{Cu})$ & Consumo energético anódico $(\mathrm{KWh} / \mathrm{Kg} \mathrm{Cu})$ \\
\hline 20 & 67 & 64 \\
50 & 59 & 58 \\
100 & 59 & 55 \\
150 & 60 & 55 \\
200 & 57 & 53 \\
250 & 58 & 52 \\
300 & 57 & 53 \\
350 & 58 & 53 \\
400 & 59 & 52 \\
\hline
\end{tabular}

Tabela 2S. Consumo energético nos testes com variação da intensidade de corrente $\left(\left[\mathrm{CO}_{3}{ }^{2-}\right]=400 \mathrm{~g} \mathrm{~L}^{-1}\right)$

\begin{tabular}{ccc}
\hline Corrente, $\mathrm{A}$ & Consumo energético catódico $(\mathrm{KWh} / \mathrm{Kg} \mathrm{Cu})$ & Consumo energético anódico $(\mathrm{KWh} / \mathrm{Kg} \mathrm{Cu})$ \\
\hline 4 & 7 & 8 \\
6 & 14 & 15 \\
8 & 17 & 20 \\
10 & 23 & 27 \\
\hline
\end{tabular}




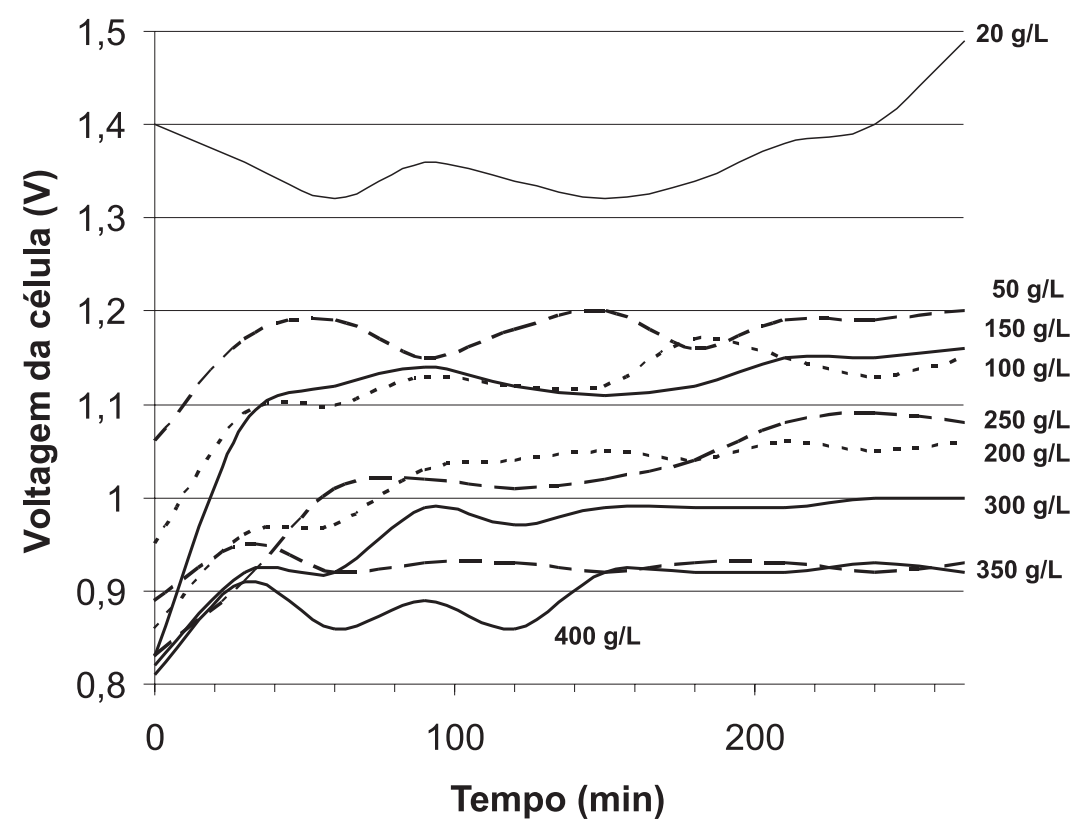

Figura 6S. Voltagem da célula nos testes onde se variou a concentração de carbonato ( $I=10 \mathrm{~A})$

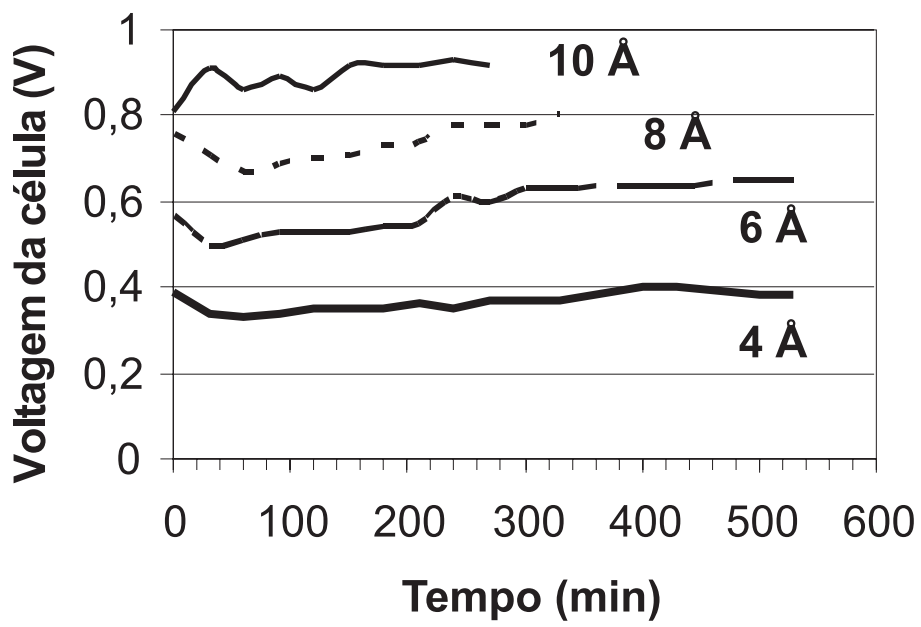

Figura 7S. Voltagem da célula nos testes de variação da intensidade da corrente $\left(\left[\mathrm{CO}_{3}{ }^{2-}\right]=400 \mathrm{~g} \mathrm{~L}^{-1}\right)$ 


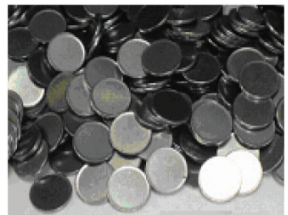

Disco de Aço (Taxa R\$0,01)
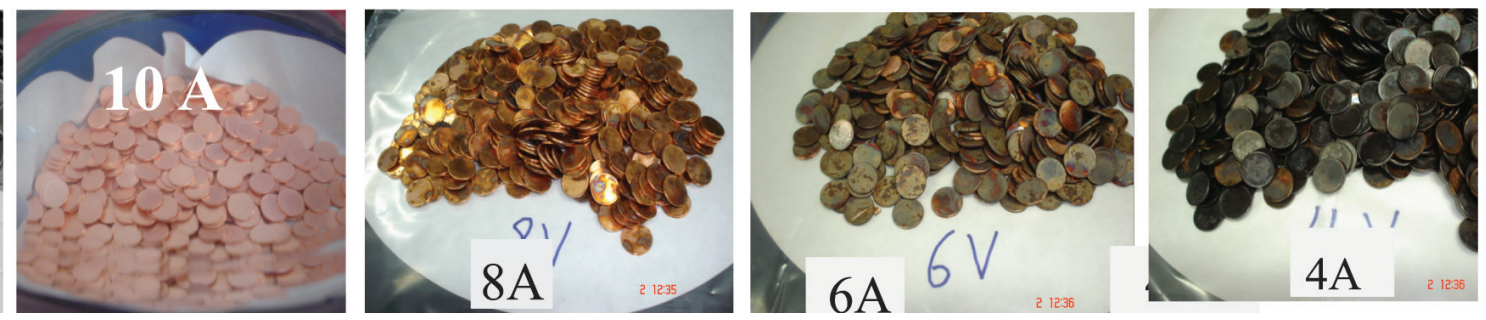

Figura 8S. Aspecto visual dos discos de aço-carbono eletrodepositados com cobre sob várias intensidades de corrente, comparados ao substrato original $\left(\left[\mathrm{CO}_{3}^{2-}\right]=400 \mathrm{~g} \mathrm{~L}^{-1}\right)$

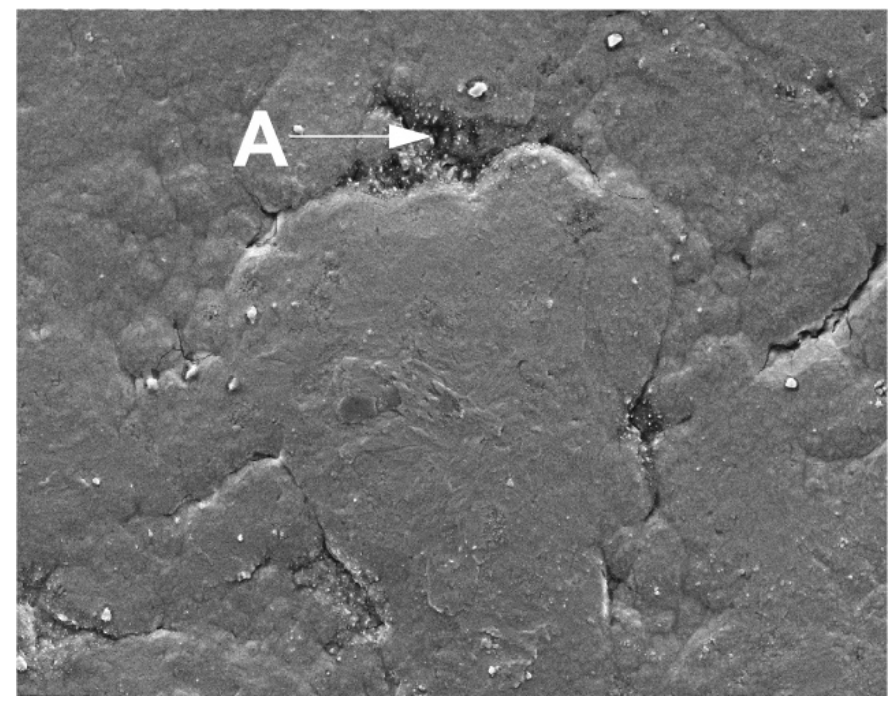

Figura 9S. Superfície do disco de aço-carbono com a cobertura deficiente dessa superfície pelo depósito de cobre eletrolítico (corrente 6 A), com áreas mostrando o substrato de aço (A) sem depósito de cobre 